\title{
Concentração de minerais no tecido queratinizado podal de equinos jovens da raça Crioula em diferentes fases de crescimento
}

[Mineral concentrations in the keratinized tissue on the feet of young Crioulo horses at different stages of growth ]

P.M. Silva ${ }^{1}$, M.R. Queiroz Filho' ${ }^{2}$ D.H. Bonemann ${ }^{3}$, A.S. Ribeiro ${ }^{3}$, F.R.P. Bruhn ${ }^{2}$, R.F. Bermudes ${ }^{1}$, A.A. Barbosa ${ }^{2 *}$, C.F. Martins ${ }^{2}$

\author{
${ }^{1}$ Aluno de pós-graduação - Faculdade Eliseu Maciel - Universidade Federal de Pelotas - Capão do Leão, RS \\ ${ }^{2}$ Faculdade de Medicina Veterinária - Universidade Federal de Pelotas - Capão do Leão, RS \\ ${ }^{3}$ Aluno de pós-graduação - Universidade Federal de Pelotas - Capão do Leão, RS
}

\section{RESUMO}

O presente estudo avaliou o perfil mineral de Cálcio $(\mathrm{Ca})$, Cobre $(\mathrm{Cu})$ e Zinco $(\mathrm{Zn})$ no estojo córneo pré e pós-desmame e sua associação com pigmentação, gênero e idade de potros da raça Crioula criados em pastagens nativas no Rio Grande do Sul. Foram coletadas amostras do casco de potros da raça Crioula 41 dias pré e 28 dias pós-desmame. Os teores de $\mathrm{Ca}, \mathrm{Cu}$ e $\mathrm{Zn}$ variaram no casco fetal $(571,0 \pm 39,4 ; 14,5 \pm 7,6$ e $130,0 \pm 30,5 \mathrm{mg} / \mathrm{kg}$, respectivamente; $\mathrm{P}<0,05)$ e no definitivo $(653,0 \pm 169,2 ; \quad 33,8 \pm 11,5$ e $69,3 \pm 36,8 \mathrm{mg} / \mathrm{kg}$, respectivamente; $\mathrm{P}<0,05)$, no pré $(620,0 \pm 184 ; 17,2 \pm 21,2$ e $103,0 \pm 75,5 \mathrm{mg} / \mathrm{kg}$, respectivamente; $\mathrm{P}<0,05)$ e no pós-desmame $(517,5 \pm 181 ; 0$ e 79,0 $441,7 \mathrm{mg} / \mathrm{kg}$, respectivamente; $\mathrm{P}<0,05)$. Houve associação positiva $(\mathrm{P}<0,05)$ com a faixa etária no pré-desmame para $\mathrm{Ca}(\mathrm{r}=0,5)$ e $\mathrm{Cu}(\mathrm{r}=0,57)$, e negativa para $\mathrm{Zn}(\mathrm{r}=-0,69 ; \mathrm{P}<0,05)$. No pós-desmame, houve associação positiva $(\mathrm{P}<0,05)$ para $\mathrm{Ca}$ $(\mathrm{r}=0,36)$ e $\mathrm{Zn}(\mathrm{r}=0,64)$ e negativa para $\mathrm{Cu}(\mathrm{r}=-0,39 ; \mathrm{P}<0,05)$. Tanto a pigmentação quanto o gênero não afetaram o perfil mineral. Conclui-se que há diferenças nas concentrações de $\mathrm{Ca}, \mathrm{Cu}$ e $\mathrm{Zn}$ na epiderme do casco de potros da raça Crioula no pré e pós-desmame, independentemente da pigmentação e do gênero, onde as concentrações de $\mathrm{Ca}$ e $\mathrm{Cu}$ aumentam com a idade, enquanto as de $\mathrm{Zn}$ diminuem.

Palavras-chave: casco, epiderme, equino, estojo córneo, metabolismo

\begin{abstract}
The aim of this study was to evaluate the mineral profile of $\mathrm{Ca}, \mathrm{Cu}$ and $\mathrm{Zn}$ in the hoof horny capsule at pre and post-weaning and its association with pigmentation, gender and age range of Crioulo foals raised in native pastures in RS. Samples were collected from the epidermis of the Crioulo foal's hoof at two times, 41 pre and 28 post-weaning. The contents of $\mathrm{Ca}, \mathrm{Cu}, \mathrm{Zn}$ Varied in the fetal hoof ( $571.0 \pm 139.4,14.5 \pm 7.6$ and $130.0 \pm 30.5 \mathrm{mg} / \mathrm{kg}$, respectively, $P<0.05)$ and definitive $(653.0 \pm 169.2$, $33.8 \pm 11.5$ and $69.3 \pm 36.8 \mathrm{mg} / \mathrm{kg}$, respectively, $P<0.05)$, in the pre $(620.0 \pm 184,17.2 \pm 21.2$ and103.0 $\pm 75.5 \mathrm{mg} / \mathrm{kg}$, respectively, $P<0.05)$ and post-weaning $(517.5 \pm 181,0.1$ and $79.0 \pm 41.7 \mathrm{mg} / \mathrm{kg}$, respectively, $P<0.05)$. There was a positive association $(P<0.05)$ with a preweaning age for $C a(r=0.5)$ and $\mathrm{Cu}(r=0.57)$ and negative for $\mathrm{Zn}(r=-0.69, P<0.05)$. In the post weaning there was a positive association $(P<0.05)$ for $\mathrm{Ca}(r=0.36)$ and $\mathrm{Zn}(r=0.64)$ and negative for $\mathrm{Cu}(r=-0.39 ; \mathrm{P}<0.05)$. Neither pigmentation nor gender affected the mineral profile. It is concluded that there are differences in $\mathrm{Ca}, \mathrm{Cu}$, $\mathrm{Zn}$ concentrations in the epidermis of foals of the crioulo breed at the pre and post weaning, regardless of pigmentation and sex, where $\mathrm{Ca}$ and $\mathrm{Cu}$ concentrations increase with age, while $\mathrm{Zn}$ concentrations decrease.
\end{abstract}

Keywords: hoof, epidermis, equine, hoof horny capsule, metabolism

Recebido em 27 de setembro de 2019

Aceito em 11 de fevereiro de 2020

*Autor para correspondência (corresponding auhtor)

E-mail: antoniobarbosa.vet@hotmail.com 


\section{INTRODUÇÃO}

A formação e a resistência do estojo córneo do casco de potros está intimamente relacionada com sua composição química e as condições nutricionais recebidas pela égua durante os períodos gestacional e lactacional (Winkler e Margerison, 2012), além da genética, do regime de criação, da estação do ano e da composição química do solo. Em torno de 65 dias de gestação, os cascos do feto equino já podem ser observados radiograficamente no útero da mãe (Curtis, 2017). Após o nascimento, inicia-se um período de quatro meses de crescimento intenso do casco (Souza et al., 2017), sendo possível observar um anel ou linha de crescimento que circunda toda a muralha, demarcando o desenvolvimento de um casco definitivo, o qual substituirá o casco fetal (Curtis et al., 2014).

Desde o nascimento, as diferenças de pigmentações são observadas no estojo córneo do casco desses indivíduos e variações foram reportadas em alguns estudos quanto às concentrações de minerais de $\mathrm{Ca}, \mathrm{Cu}$ e $\mathrm{Zn}$ em equinos das raças Pantaneira, Mangalarga Marchador (Faria et al., 2005) e Campeiro (Mendes et al., 2017 ).

Dessa forma, a epiderme, por ser um tecido avascular, é nutrida por difusão e diferença de gradiente de concentração através da derme, tecido altamente vascularizado e inervado, localizado imediatamente abaixo dela (Sisson, 1986; Tomlinson et al., 2004). Acredita-se que a concentração mineral esteja intimamente associada à integridade e qualidade da epiderme queratinizada (Ballantine et al., 2002), ou seja, a qualidade do tecido queratinizado da epiderme depende da nutrição (Mülling et al., 1999). Os elementos minerais são essenciais para o metabolismo do organismo e são cofatores para diversas enzimas que atuam em processos catalíticos (Cintra, 2016), pois caracterizam-se por serem substâncias inorgânicas que compõem os alimentos estando divididas em dois grupos: macrominerais, aqueles necessários em concentrações relativamente altas (g por dia); e os microminerais, que são imprescindíveis em pequenas concentrações (mg por dia).

Assim, alguns minerais desempenham papel fundamental na nutrição do casco, como o cálcio $\left(\mathrm{Ca}^{2+}\right.$, macromineral $)$, que regula os processos de queratinização e cornificação dos queratinócitos por meio da regulação das transglutaminases, enzimas que são ativadas no final do processo de queratinização, na transição entre o estrato granuloso e o córneo. Também são responsáveis pela reticulação dos filamentos de queratina com proteínas para formação do envelope córneo, reforçando o citoesqueleto dos queratinócitos (Bragulla e Homberger, 2007).

Já o cobre $\left(\mathrm{Cu}^{2+}\right)$ tem relevante função catalítica como cofator do citocromo $\mathrm{C}$ oxidase, enzima terminal da cadeia transportadora de elétrons, apresentando relação direta com a respiração e a fosforilação oxidativa celular. $O$ cobre é componente do complexo $\mathrm{Cu} / \mathrm{Zn}$ superóxido desmutase, uma importante enzima que previne a oxidação dos lipídios da substância cementante intercelular do tecido queratinizado (Van Riet $e t$ al., 2013).

Outro nutriente essencial à queratinização é o zinco $\left(\mathrm{Zn}^{3+}\right.$, micromineral) (Mülling et al., 1999; Smart e Cymbaluk, 1997). Estruturalmente o Zn é indispensável, pois é cofator dos Zinc Fingers, proteínas que utilizam o zinco para estabilização de suas estruturas e que têm relação direta com a síntese proteica necessária à formação dos filamentos de queratina (Van Riet et al., 2013). Esse micromineral catalisa diversas enzimas participantes do processo de queratinização, como a RNA polimerase, a fosfatase alcalina, o álcool desidrogenase.(Tomlinson et al., 2004). Além disso regula a proteína quinase $\mathrm{C}$ para a geração de energia, atua na calmodulina, responsável pelo transporte do $\mathrm{Ca}$, e, indiretamente, participa da atividade das transglutaminases que fazem parte da composição da enzima superóxido desmutase, conforme supracitado (Van Riet et al., 2013).

Baseado na hipótese de que há variação nas concentrações dos minerais na epiderme do casco de potros pertencentes à raça Crioula, criados em pastagens nativas, o presente estudo avaliou o perfil dos minerais $\mathrm{Ca}, \mathrm{Cu}$ e $\mathrm{Zn}$ na epiderme dos cascos fetais e definitivos, pré e pós-desmame, analisando as diferenças na composição química quanto às características de pigmentação e sua associação com gênero e faixa etária dos potros pertencentes à raça Crioula. 


\section{MATERIAL E MÉTODOS}

Este estudo foi aprovado pelo Comitê de Ética e Bem-Estar (Ceea) da Universidade Federal de Pelotas (UFPel), sob o nº 101973/2017. Quarenta e um potros da raça Crioula, nascidos de setembro a janeiro, nas estações de primavera/verão, foram selecionados de cinco (5) criatórios localizados em municípios distintos no Rio Grande do Sul, Brasil (Capão do Leão, Jaguarão, Arroio Grande, Dilermando de Aguiar e Santa Maria). Os potros foram mantidos com as éguas em pastagens naturais, compostas por, principalmente, Paspalum notatum (gramaforquilha), Desmodium incanum (pega-pega), Axonopus compressus (grama-tapete) Paspalum dilatatum (capim-melador) e Cynodon dactylon (grama-bermudas), com acesso ad libitum a água.

O estudo foi realizado no período de dezembro de 2017 a novembro de 2018 e consistiu em dois momentos de coleta (pré e pós-desmame). No pré-desmame, utilizou-se 41 potros (16 machos e 25 fêmeas)do nascimento aos 186 dias de vida, nas estações verão e outono. No pós-desmame, foram utilizados 28 potros (já avaliados no prédesmame), com idade entre 280 e 364 dias de vida, a partir de 60 dias após o desmame. A redução no número de animais utilizados no estudo durante o período de pós-desmame ocorreu por óbito ou comercialização.

Antes da coleta, os cascos foram lavados com detergente isento de minerais e secos com álcool absoluto. As amostras da epiderme do casco dos potros da raça Crioula foram coletadas na face dorsoproximal de ambos os membros anteriores, por intermédio de uma grosa (Nicholson ${ }^{\odot}, 14$ " $350 \mathrm{~mm}$ ), e foram obtidas, pelo menos, dois gramas $(2 \mathrm{~g})$ de farelo da muralha do casco. Para essa coleta, foi descartada a porção superficial do casco, a fim de evitar contaminação de minerais do ambiente. Posteriormente, as amostras foram acondicionadas em tubos de polipropileno tipo Falcon de 50ml, devidamente identificados e lacrados.

Os teores de cálcio, cobre e zinco foram determinados pelo método utilizado no Exercício Colaborativo CRM-Agro (2016) para validação de Materiais de Referência Certificados, de acordo com as normas do Inmetro. No entanto, algumas adaptações foram necessárias para melhor decomposição das amostras. Assim, foi realizada a coleta de aproximadamente $250 \mathrm{mg}$ de amostra da epiderme do casco diretamente em tubos de borosilicato. Logo, adicionaram-se 5,0mL de $\mathrm{HNO}_{3} 65 \%$ v/v bidestilado, acoplou-se o sistema de refluxo aos tubos, conforme descrito por Oreste et al. (2013). Após esse procedimento, as amostras foram colocadas em bloco digestor a $150^{\circ} \mathrm{C}$, por duas horas.

Passado esse período, as amostras apresentavam uma coloração intensa, característica da decomposição da amostra. Para deixar a solução mais límpida, após esfriar, adicionou-se 1,0mL de $\mathrm{H}_{2} \mathrm{O}_{2} 30 \% \mathrm{v} / \mathrm{v}$, e ela foi levada ao bloco digestor por mais 30 minutos, na mesma temperatura. Posteriormente, as amostras foram transferidas para frascos de polipropileno e aferidas a $20 \mathrm{~mL}$ com água desionizada. Os elementos $\mathrm{Ca}, \mathrm{Cu}$ e $\mathrm{Zn}$ foram quantificados pela técnica de espectrometria de absorção atômica em chama (F AAS), modelo AAnalyst 200 (Perkin Elmer, Singapura), equipado com lâmpadas de cátodo oco para cada analito (Lumina, Perkin Elmer) e uma lâmpada de arco de deutério como corretor de fundo, exceto para análise de $\mathrm{Ca}$.

As soluções padrão utilizadas na calibração instrumental foram obtidas de suas respectivas soluções estoque de $1000 \mathrm{mg} / \mathrm{L}$, para $\mathrm{Ca}$ e $\mathrm{Cu}$, e de $10000 \mathrm{mg} / \mathrm{L}$, para $\mathrm{Zn}$, preparadas em meio de $\mathrm{HNO}_{3}$. Para a determinação de $\mathrm{Ca}$ por F AAS, uma solução de cloreto de césio $1 \%(\mathrm{~m} / \mathrm{v})$ e cloreto de lantânio $10 \%(\mathrm{~m} / \mathrm{v})$ foi adicionada às amostras como supressor de ionização e formação de óxidos, respectivamente, em que se obteve o limite de detecção (LD) para $\mathrm{Ca}$ de $0,048 \mathrm{mg} / \mathrm{L}$, para $\mathrm{Cu}$ de $0,012 \mathrm{mg} / \mathrm{L}$ e para $\mathrm{Zn}$ de $0,0045 \mathrm{mg} / \mathrm{L}$.

A composição química do casco no tempo, desde o nascimento até a troca do casco fetal ou cápsula decídua (Curtis et al., 2014, 2017), foi determinada levando-se em consideração a localização da linha de crescimento fetal (Fig. 1) em relação à coroa do casco. Foram considerados três estágios de avaliação de estojo córneo (Fig. 2), sendo o primeiro quando a linha se distanciava até $2,3 \mathrm{~cm}$ da coroa do casco (Fig. 2; A), em potros com idade até 47 dias; o segundo estágio, com a presença da linha ocupando mais de 2,3 a 4,6cm (Fig. 2; B), com idade acima de 47 dias até 126 dias de vida; e o terceiro estágio, 
com a linha distanciada em mais de $4,6 \mathrm{~cm}$ da coroa do casco (Fig. 2; C), com os potros apresentando idade acima de 126 dias até em torno de 186 dias de vida.

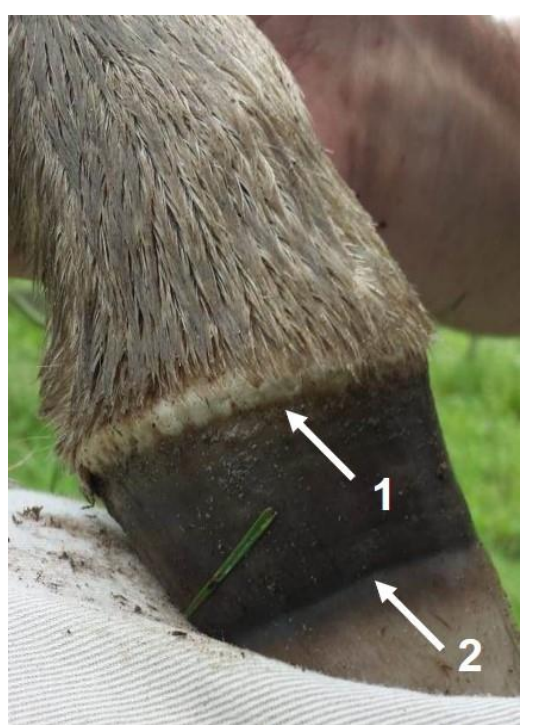

Figura 1. Localização da linha de crescimento fetal ou cápsula decídua em relação à coroa do casco de potro da raça Crioula com 66 dias. Em (1) coroa e em (2) linha de crescimento fetal.

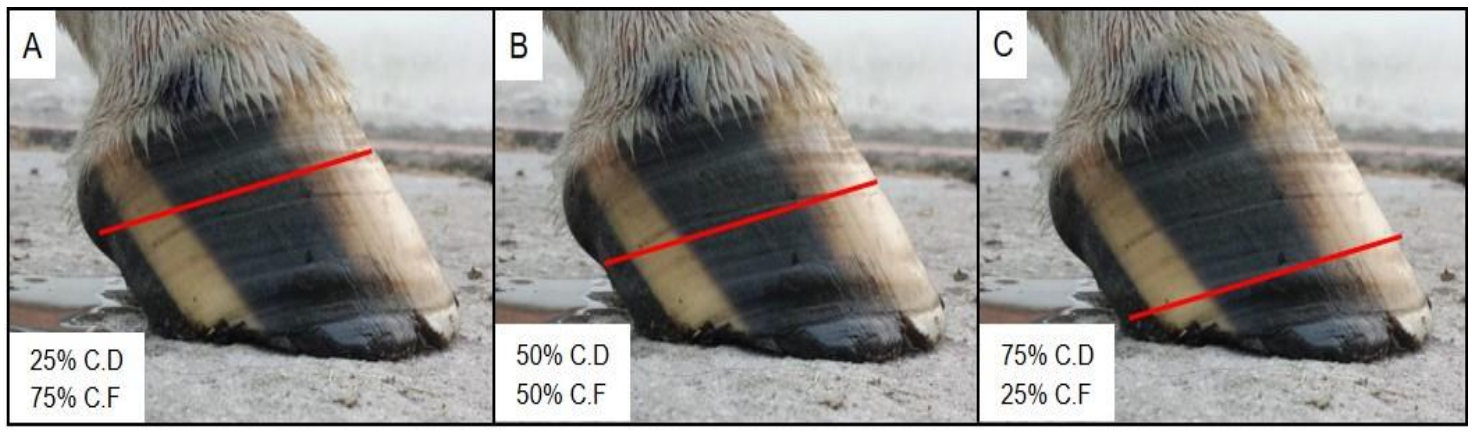

Figura 2. Cascos de potros da raça Crioula desde o nascimento até a troca do casco fetal, levando-se em consideração estágio da linha de crescimento fetal. Linha de crescimento fetal no $1^{\circ}$ estágio (A); linha de crescimento fetal no $2^{\circ}$ estágio (B); linha de crescimento fetal no $3^{\circ}$ estágio $(\mathrm{C}) ; \mathrm{CD}=$ casco definitivo; $\mathrm{CF}=$ casco fetal

Para análise da coloração dos cascos, utilizou-se como metodologia a observação visual da pigmentação do casco, sendo consideradas três (3) cores: preto (Fig. 3; A), branco (Fig. 3; B) e misto (cascos que continham as duas cores e rajados) (Fig. 3; C).

Inicialmente, as variáveis quantitativas foram submetidas a testes de normalidade de Kolmogorov-Smirnov. Depois de verificada ausência na distribuição normal, as comparações dos teores de $\mathrm{Ca}, \mathrm{Cu}$ e $\mathrm{Zn}$ entre cascos fetal e definitivo e o gênero foram feitas por meio de testes de Mann-Whitney. As comparações dos teores com os diferentes tipos de pigmentação (branco, preto e misto) e entre os estágios de desenvolvimento do casco foram feitas por meio de testes de Kruskal-Wallis, seguidas da comparação múltipla por meio de testes de Dunn. Já as relações entre os teores dos nutrientes e a idade (dias) foram determinadas por meio do teste de correlação de Spearman. Todas as análises foram realizadas no software SPSS 20.0, considerando-se um nível mínimo de confiança de $95 \%(\mathrm{P}<0,05)$. 


\section{Concentração de minerais...}

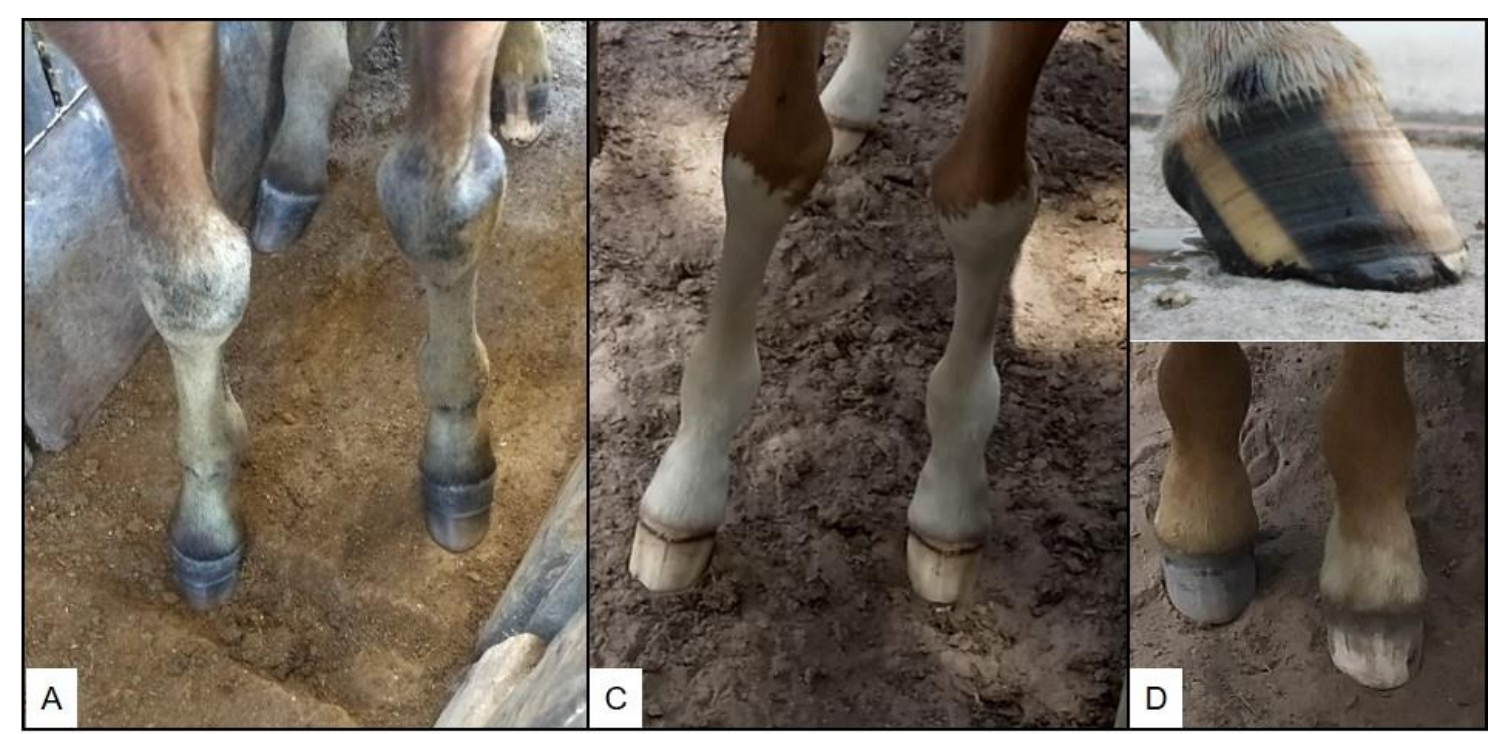

Figura 3. Pigmentação de cascos de potros da raça Crioula. Casco preto (A); casco branco (B); casco misto (C).

\section{RESULTADOS}

Variações ocorreram nas concentrações minerais do $\mathrm{Ca}, \mathrm{Cu}$ e $\mathrm{Zn}$ entre o casco fetal e o definitivo $(\mathrm{P}<0,05)($ Tab. 1), sendo as concentrações de $\mathrm{Ca}$ e $\mathrm{Cu}$ no casco fetal inferiores $(\mathrm{P}<0,05)$ às concentrações na epiderme do casco definitivo. Resultado inverso foi verificado para as concentrações de $\mathrm{Zn}$.

A composição química da epiderme do casco variou com o estágio de desenvolvimento dos cascos dos potros, desde o nascimento até a troca do casco fetal para o casco definitivo $(\mathrm{P}<0,05$; Tab. 2). A concentração de $\mathrm{Ca}$ e $\mathrm{Cu}$ foi semelhante quando a linha de crescimento estava localizada no primeiro e segundo terços do casco, mas diferenças foram registradas quando ela atingiu seu terço inferior. Já as concentrações de $\mathrm{Zn}$ variaram entre as três diferentes fases de desenvolvimento dos cascos dos potros da raça Crioula ( $\mathrm{P}<0,05$; Tab. 2).

Variações ocorreram na composição mineral de $\mathrm{Ca}$ e $\mathrm{Cu}$ da epiderme do casco nos períodos pré e pós-desmame ( $\mathrm{P}<0,05$; Tab. 3), estando, no pósdesmame, as concentrações do micromineral $\mathrm{Cu}$ reduzidas. Já o Zn não variou entre os períodos estudados (Tab. 3).

Tabela 1. Composição química (mediana) da epiderme dos cascos fetal e definitivo de potro da raça Crioula em aleitamento $(\mathrm{mg} / \mathrm{kg})$

\begin{tabular}{llll} 
& \multicolumn{1}{c}{ Cálcio $(\mathrm{mg} / \mathrm{kg})^{*}$} & \multicolumn{1}{c}{ Cobre $(\mathrm{mg} / \mathrm{kg})^{*}$} & \multicolumn{1}{c}{ Zinco $(\mathrm{mg} / \mathrm{kg})^{*}$} \\
\hline Casco fetal & $571^{\mathrm{b}} \pm 139,4$ & $14.5^{\mathrm{b}} \pm 7,6$ & $130^{\mathrm{a}} \pm 30,5$ \\
Casco definitivo & $653^{\mathrm{a}} \pm 169,2$ & $33.8^{\mathrm{a}} \pm 11,5$ & $69.3^{\mathrm{b}} \pm 36,8$ \\
\hline
\end{tabular}

*Medianas seguidas de letras diferentes na mesma coluna diferem estatisticamente $(\mathrm{P}<0,05)$.

Tabela 2. Composição química (mediana) da epiderme do casco de potros da raça Crioula lactantes desde o nascimento até a troca do casco fetal, levando-se em consideração a idade dos potros e a presença da linha de crescimento fetal

\begin{tabular}{|c|c|c|c|c|}
\hline Estágios & Idade (dias) $^{*}$ & Cálcio $(\mathrm{mg} / \mathrm{kg})^{*}$ & Cobre $(\mathrm{mg} / \mathrm{kg})^{*}$ & Zinco $(\mathrm{mg} / \mathrm{kg})^{*}$ \\
\hline $1^{\circ}(25 \% \mathrm{CD} ; 75 \% \mathrm{CF})$ & Até 47 & $571^{\mathrm{b}} \pm 112,7$ & $15,3^{\mathrm{b}} \pm 2,2$ & $151^{\mathrm{a}} \pm 11,4$ \\
\hline $2^{\circ}(50 \% \mathrm{CD} ; 50 \% \mathrm{CF})$ & 48 a 126 & $581^{\mathrm{b}} \pm 145,2$ & $12,5^{\mathrm{b}} \pm 8,7$ & $105,5^{\mathrm{b}} \pm 21,4$ \\
\hline $3^{\circ}(75 \% \mathrm{CD} ; 25 \% \mathrm{CF})$ & 127 a 186 & $714^{\mathrm{a}} \pm 181,6$ & $34,3^{\mathrm{a}} \pm 0,4$ & $58,5^{\mathrm{c}} \pm 35,5$ \\
\hline
\end{tabular}

${ }^{*}$ Medianas seguidas de letras diferentes na mesma coluna diferem estatisticamente $(\mathrm{P}<0,05)$.

$\% \mathrm{CD}=$ percentagem casco definitivo; $\% \mathrm{CF}=$ percentagem casco fetal. 
Tabela 3. Composição química (mediana) da epiderme do casco pré e pós-desmame de potros da raça Crioula $(\mathrm{mg} / \mathrm{kg})$

\begin{tabular}{llll} 
& Cálcio $(\mathrm{mg} / \mathrm{kg})^{*}$ & ${\text { Cobre }(\mathrm{mg} / \mathrm{kg})^{*}}^{*}$ & Zinco $(\mathrm{mg} / \mathrm{kg})^{*}$ \\
\hline Pré-desmame & $620^{\mathrm{a}} \pm 184$ & $17,2^{\mathrm{a}} \pm 21,2$ & $103^{\mathrm{a}} \pm 75,5$ \\
Pós-desmame & $517,5^{\mathrm{b}} \pm 181$ & $<0,012$ & $79^{\mathrm{a}} \pm 41,7$ \\
Mediana & $571 \pm 253$ & $12,7 \pm 33$ & $89 \pm 63$ \\
\hline
\end{tabular}

${ }^{*}$ Medianas seguidas de letras diferentes na mesma coluna diferem estatisticamente $(\mathrm{P}<0,05)$.

As concentrações de microminerais na epiderme do casco de potros da raça Crioula de pigmentação distinta, durante as fases fetal e definitiva, foram semelhantes $(\mathrm{P}>0,05)$, não havendo diferença também entre gêneros $(\mathrm{P}>0,05)$. Foram significativos os coeficientes de correlação entre a idade dos potros e a composição química mineral do estojo córneo $(\mathrm{P}<0,05)$. Podem-se verificar coeficientes positivos para $\mathrm{Ca}$ e $\mathrm{Cu}(\mathrm{r}=0,50$ e $\mathrm{r}=0,57$, respectivamente, $\mathrm{P}<0,05)$ e negativo para $\mathrm{Zn}(\mathrm{r}=$ $-0,69 ; \mathrm{P}<0,05)$, ou seja, os teores de $\mathrm{Ca}$ e $\mathrm{Cu}$ aumentaram com o desenvolvimento dos potros durante o período lactacional, enquanto os teores de $\mathrm{Zn}$ reduziram com a idade.

Durante período pós-lactacional, destaca-se a correlação negativa do mineral $\mathrm{Cu}$. Nesse período pós-desmame, $\mathrm{Ca}$ e $\mathrm{Zn}$ apresentaram correlação positiva $(\mathrm{r}=0,36 \mathrm{e} \quad \mathrm{r}=0,64$, respectivamente, $\mathrm{P}<0,05)$, enquanto os teores de $\mathrm{Cu}(\mathrm{r}=-0,39 ; \mathrm{P}<0,05)$ diminuíram conforme os potros foram se desenvolvendo.

\section{DISCUSSÃO}

O conhecimento das concentrações e da variabilidade desses minerais, responsáveis pela formação da epiderme do casco de equinos, mais precisamente potros da raça Crioula criados em sistema extensivo durante e após seu período lactacional, pode fornecer importantes subsídios na fundamentação do uso de suplementos e auxiliar no manejo nutricional desses animais durante o crescimento.

Neste estudo, pôde-se inferir que ocorreu variabilidade nas concentrações dos minerais na epiderme do casco definitivo, em relação ao fetal (Tab. 1). Trata-se de informações relevantes e desconhecidas até o atual momento e que provavelmente estejam vinculadas à variação na disponibilidade de micronutrientes nas fontes nutricionais, que foram distintas entre os períodos durante a lactação e pós-lactacional.
Ao nascimento, o potro deixou de ser nutrido via placenta e passou a receber como principal fonte de alimentação o leite materno somado ao consumo de volumoso (campo nativo) nos meses subsequentes. Essas variações denotam a importância do equilíbrio nutricional desses indivíduos em desenvolvimento, que, se expostos a condições inadequadas, caracterizam possibilidade de falhas na formação estrutural do estojo córneo precocemente, com implicações na performance, injúrias e claudicações, quando esses animais se tornarem adultos e atletas. Esses problemas foram identificados por Barbosa et al. (2016), que, apesar de terem realizado estudo em vacas leiteiras, associaram variabilidade na composição química da epiderme dos cascos de vacas lactantes com incidência de claudicação.

Considerando-se o NRC (Nutrientes..., 2007) para equinos, adotando-se como critérios peso, idade e categorias, há exigência para suprir a necessidade mensal para potros até dois (2) meses de $4.000 \mathrm{mg} / \mathrm{kg} / \mathrm{dia}$ de Ca, $20 \mathrm{mg} / \mathrm{kg} / \mathrm{dia}$ de $\mathrm{Cu}$ e $80 \mathrm{mg} / \mathrm{kg} / \mathrm{dia}$ de $\mathrm{Zn}$. Neste estudo, verificouse que o estojo córneo dos potros (com mesma idade) apresentou $571 \mathrm{mg} / \mathrm{kg} /$ dia de $\mathrm{Ca}$, $15,3 \mathrm{mg} / \mathrm{kg}$ de $\mathrm{Cu}$ e $151 \mathrm{mg} / \mathrm{kg}$ de $\mathrm{Zn}$ (Tab. 2), representando $14,3 \%, 76,5 \%$ e $188,7 \%$, respectivamente, das exigências mensais para manutenção desses animais. Assim, essas informações favorecem o aperfeiçoamento dos regimes alimentares dessa categoria em desenvolvimento.

Após o nascimento, inicia-se um período de quatro meses de crescimento intenso do casco (Souza et al., 2017), sendo possível observar um anel ou linha de crescimento que circunda toda a muralha. Tal linha demarca o desenvolvimento de um casco definitivo, que substituirá o casco fetal (casco desenvolvido em ambiente intrauterino) (Curtis et al., 2014). Em um estudo realizado por Faria et al. (2005), em cascos de equinos da raça Pantaneira, os autores não verificaram diferenças entre os teores de $\mathrm{Ca}, \mathrm{Cu}$ e $\mathrm{Zn}$, resultados distintos dos observados no 
presente estudo, que, apesar de semelhança nas concentrações de $\mathrm{Ca}$ e $\mathrm{Cu}$ quando a linha de crescimento estava localizada no primeiro e segundo terços do casco (Tab. 2), diferenças na composição química da epiderme do casco foram observadas quando esta atingiu o terço inferior (potros acima de 127 dias de vida $(\mathrm{P}<0,05$; Tab. 2).

Já as concentrações de $\mathrm{Zn}$ variaram entre as diferentes fases de desenvolvimento dos cascos dos potros da raça Crioula ( $\mathrm{P}<0,05$; Tab. 2). A variabilidade nas concentrações dos minerais na epiderme do casco definitivo, em relação ao fetal, caracteriza as diferenças em sua constituição, que provavelmente está vinculada às mudanças nutricionais ao longo do período lactacional dos potros da raça Crioula, que, até 60 dias, fundamenta-se, principalmente, na ingestão de leite, pois o consumo de volumoso (Bolzan, 2016) é estabelecido com maior propriedade entre 60 e 80 dias, momento em que os animais consomem mais matéria seca (MS). Portanto, as variações nas concentrações dos minerais estudados no estojo córneo de potros da raça Crioula em desenvolvimento confirmam a importância e participação dos minerais na constituição e no fortalecimento dos tecidos epidérmicos em formação (Ballantine et al., 2002; Hintz, 1983; Mülling et al., 1999).

Schryver et al. (1986) observaram redução de $41 \%$ na concentração de zinco no leite de éguas Puro-Sangue nas primeiras cinco semanas de lactação. Lonnerdal (1991) estudou a concentração mineral no leite materno em humanos e também relatou diminuição progressiva dos teores de zinco ao longo do período lactacional. Quarenta e cinco dias pósparto, esse autor observou que os teores de zinco do leite atingiram um valor de $25 \%$ dos valores iniciais da lactação e, após seis meses, $60 \%$ dos teores médios apresentados nos primeiros 15 dias de lactação. Apesar de não terem sido monitoradas as concentrações minerais no leite materno das éguas da raça Crioula, resultados dos estudos mencionados podem explicar a redução das concentrações dessa variável (Zn) durante o período lactacional dos seus descendentes (Tab. 2).

As diferenças nas concentrações minerais entre os períodos pré e pós-desmame (Tab. 3) estão vinculadas a nutrição e a fatores ambientais, considerando-se as diferenças fisiográficas das regiões em que os animais foram criados, pois fatores como: heterogeneidade, diversidade de espécies forrageiras e estágio de crescimento dos pastos, vinculados às características físicoquímicas do solo e às estações do ano, são razões de diversidade regional que impactam oscilações na concentração desses minerais nos alimentos oferecidos a esses potros (Dittrich et al., 2010). Isso não quer dizer que os animais estão sofrendo restrição alimentar, mas há variação na composição de sua dieta, refletindo no tecido epidérmico do casco.

No período de aleitamento, as amostras foram coletadas nas estações de verão e outono; enquanto, após desaleitamento, as coletas foram realizadas nas estações de inverno e primavera, o que justifica as diferenças observadas (Tab. 3). O maior teor do mineral $\mathrm{Ca}$ no estojo córneo durante a lactação $(620 \mathrm{mg} / \mathrm{kg})$, quando comparada com o pós-desmame $(517,5 \mathrm{mg} / \mathrm{kg})$ (Tab. 3), caracteriza o leite materno, que apresenta elevadas concentrações de $\mathrm{Ca}$ (média de $850 \mathrm{mg} / \mathrm{kg}$ de Ca) (Rangel et al., 2015) como principal fonte desse nutriente à dieta, refletindo positivamente nas concentrações desse mineral na epiderme do casco. Mesmo que as variáveis associadas ao leite não tenham sido consideradas neste estudo, isso não impossibilita a determinação do real efeito sobre as concentrações dos minerais no estojo córneo.

Faria et al. (2005), ao analisarem os teores de minerais do casco de éguas das raças Mangalarga Marchador e Pantaneira de cinco a 10 anos de idade, criadas a pasto, no estado de Minas Gerais, observaram teores médios no casco de $232,7 \mathrm{mg} / \mathrm{kg}$ de $\mathrm{Ca}, 4,42 \mathrm{mg} / \mathrm{kg}$ de $\mathrm{Cu}$ e $67,16 \mathrm{mg} / \mathrm{kg}$ de $\mathrm{Zn}$, para a raça Mangalarga Marchador, e de $567,65 \mathrm{mg} / \mathrm{kg}$ de $\mathrm{Ca}$, $23,56 \mathrm{mg} / \mathrm{kg}$ de $\mathrm{Cu}$ e $116,2 \mathrm{mg} / \mathrm{kg}$ de $\mathrm{Zn}$, para a raça Pantaneiro, resultados esses, considerandose os teores dos minerais $\mathrm{Ca}$ e $\mathrm{Zn}$, próximos aos encontrados no presente estudo (valores medianos de $571 \mathrm{mg} / \mathrm{kg}$ de $\mathrm{Ca}, 12,7 \mathrm{mg} / \mathrm{kg}$ de $\mathrm{Cu}$ e $89 \mathrm{mg} / \mathrm{kg}$ de $\mathrm{Zn}$; Tab. 3), apesar das diferenças de grupo genético, faixas etárias, bem como de regiões. Mendes et al. (2017), ao avaliarem as concentrações minerais de $\mathrm{Ca}, \mathrm{Cu}$ e $\mathrm{Zn}$, oriundos da muralha dos cascos de equinos adultos da raça Campeiro, encontraram 178,79 $\pm 137,16 \mathrm{mg} / \mathrm{kg}$, $3,51 \pm 1,61 \mathrm{mg} / \mathrm{kg}$ e $163,88 \pm 36,7 \mathrm{mg} / \mathrm{kg}$, respectivamente, não corroborando os valores 
verificados no presente estudo $(571 \pm 253$, $12,7 \pm 33$ e $89 \pm 63 \mathrm{mg} / \mathrm{kg}$, respectivamente; Tab. 3). Diante disso, a variação de faixa etária e grupo genético, entre os estudos científicos, poderia explicar a diferença dos valores encontrados, sem descartar as interferências dos níveis nutricionais dos campos nativos disponibilizados serem distintas.

Quando estudaram a diferença de pigmentação do casco de equinos nas raças Pantaneiro e Mangalarga Marchador, Faria et al. (2005), e Mendes et al. (2017 ), na raça Campeiro, esses autores verificaram que não há influência da concentração dos minerais na epiderme do casco em relação à pigmentação do casco equino. Os achados determinados no presente estudo compartilham a mesma opinião, podendo-se inferir que não há diferenças nas concentrações de microminerais na epiderme do casco dos potros da raça Crioula de pigmentação distinta $(\mathrm{P}>0,05)$, independentemente da diferença entre raças e localidade geográfica de criação.

Em um estudo com leite equino da raça PuroSangue Inglês, as concentrações de $\mathrm{Ca}$ $(930 \mathrm{mg} / \mathrm{kg}$ por dia) e $\mathrm{Cu}(0,2 \mathrm{mg} / \mathrm{kg}$ por dia $)$ foram insuficientes no leite materno para as necessidades do potro durante a lactação (Grace et al., 1999), tendo o organismo que mobilizar outras fontes (ossos, rim) de absorção de Ca. Quando o potro se torna herbívoro, os teores desses minerais tendem a aumentar, se as forragens forem de boa qualidade (Pereira et al., 2017). No presente estudo, houve aumento das concentrações de $\mathrm{Ca}$ e $\mathrm{Cu}$ na epiderme do casco, com o aumento da faixa etária dos potros $(\mathrm{r}=$ $0,50$ e $r=0,57$, respectivamente; $\mathrm{P}<0,05)$, provavelmente relacionada à maior ingestão de sólidos (volumoso). Considerando-se os aspectos analisados, o atual estudo providenciou informações essenciais que facilitarão decisões quanto à necessidade de ingestão de minerais como $\mathrm{Ca}, \mathrm{Cu}$ e $\mathrm{Zn}$ para prevenção de possíveis injúrias aos cascos de equinos da raça Crioula.

\section{CONCLUSÃO}

A concentração dos minerais $\mathrm{Ca}, \mathrm{Cu}$ e $\mathrm{Zn}$ é diferente entre casco fetal e casco definitivo de potros da raça Crioula e entre períodos pré e pósdesmame, sendo independente de sua pigmentação e gênero. As concentrações dos minerais $\mathrm{Ca}$ e $\mathrm{Cu}$ na epiderme do casco de potros da raça Crioula aumentam com a idade do potro, enquanto a de $\mathrm{Zn}$ reduz.

\section{AGRADECIMENTOS}

Os autores agradecem à Coordenação de Aperfeiçoamento de Pessoal de Nível Superior (Capes), Brasília, Brasil, pelas bolsas a P.M. Silva; A.A.S. Xavier e D. H. Bonemann; aos proprietários dos animais por permitirem a coleta de dados em seus estabelecimentos - Cabanha Nobleza Gaúcha, Cabanha Don Tato, Cabanha Destacada, Cabanha SJ Palanque, Cabanha Rincão do Telho, Cabanha Santa Mathilde e Cabana Porteira de Ferro; à Associação Brasileira de Criadores de Cavalos Crioulos (ABCCC), pelo apoio financeiro que possibilitou a execução do processo; ao Laboratório de Metrologia Química da UFPel (LabMeQui), pela disponibilidade nas análises químicas e por fim a Universidade Federal de Pelotas.

\section{REFERÊNCIAS}

BALLANTINE, H.; SOCHA, M.; TOMLINSON, D.A.D. et al. Effects of feeding complexed zinc, manganese, copper, and cobalt to late gestation and lactating dairy cows on claw integrity, reproduction, and lactation performance. Prof. Anim. Sci., v.18, p.211-218, 2002.

BARBOSA, A.A.; LUZ, G.B.; RABASSA, V.R. et al. Concentration of minerals in the hoof horny capsule of healthy and lame dairy cows. Semin. Ciênc. Agrár., v.37, p.1423-1429, 2016.

BOLZAN, A.M.S. Aprendizado do forrageamento e desenvolvimento da dieta de potros. 2016. 89f. Dissertação (Mestrado em Medicina Animal: Equinos) - Faculdade de Veterinária, Universidade Federal do Rio Grande do Sul, Porto Alegre, RS.

BRAGULLA, H.H.; HOMBERGER, D.G. The role of the specific, profilaggrin-containing keratohyalin granules in the developing epidermis of the fetal horse hoof. Pferdeheilkunde, v.23, p.5, 2007.

CINTRA, A.G.C. Alimentação equina: nutrição, saúde e bem-estar. Rio de Janeiro: Roca, 2016. $354 p$. 
CRM-AGRO MATERIAIS DE REFERÊNCIA PARA AGRICULTURA, PECUÁRIA E TOXICOLOGIA. Exercício Colaborativo CRMAgro FT_012016. 2016.Universidade de São Paulo - Centro de Energia Nuclear na Agricultura - Laboratório de Radioisótopos, Piracicaba, SP.

CURTIS, S.; MARTIN, J.; HOBBS, S. The hoof renewal time of $\mathrm{t}$ horoughbred foals from birth. J. Equine Vet. Sci., v.46, p.39, 2014.

CURTIS, S.J. The effect of loading upon hoof wall growth and hoof shape in the Thoroughbred foal. 2017. 200f. Tesis (Doctor em Filosofia) Schoolof Sport, University of Central Lancashire, Preston, UK.

DITTRICH, J.R.; MELO, H.A.; AFONSO, A. et al. Comportamento ingestivo de equinos e a relação com o aproveitamento das forragens e bem-estar dos animais. Rev. Bras. Zootec., v.39, p.130-137, 2010.

FARIA, G.; REZENDE, A.; SAMPAIO, I. et al. Composição química dos cascos de eqüinos das raças Pantaneira e Mangalarga Marchador. Arq. Bras. Med. Vet. Zootec., v.57, p.697-701, 2005.

GRACE, N.; PEARCE, S.; FIRTH, E. et al. Concentrations of macro-and micro-elements in the milk of pasture-fed Thoroughbred mares. Aust. Vet. J., v.77, p.177-180, 1999.

HINTZ, H.F. Horse nutrition: a practical guide. Nova Yorqui: Arco Pub, 1983. 228p.

LONNERDAL, B. Concentrations, compartmentation, and bioavailability of trace elements in human milk and infant formula. Nestlé Nutr. Inst., v.23, p.153-171, 1991.

MATERIAIS de referência para agricultura, pecuária e toxicologia. Exercício colaborativo. Piracicaba, SP: CRM-AGRO, 2016.

MENDES, R.P.; SOUZA, A.F.; LAUS, R. et al. Biometria do equilíbrio podal e composição química dos cascos de equinos da raça Campeiro. In: SEMINÁRIO DE INICIAÇÃO CIENTÍFICA, 27., 2017, Santa Catarina. Anais... Santa Catarina: [s.n.], 2017.

MÜLLING, C.; BRAGULLA, H.; REESE, S. et al. How structures in bovine hoof epidermis are influenced by nutritional factors. Anat. Histol. Embryol., v.28, p.103-108, 1999.
NUTRIENTS requirements of domestic horses. 6.ed. Washignton D.C: National Academy Press, 2007. 341p.

ORESTE, E.Q.; JESUS, A.; OLIVEIRA, R.M. et al. New design of cold finger for sample preparation in open system: determination of $\mathrm{Hg}$ in biological samples by CV-AAS. Microchem. J., v.109, p.5-9, 2013.

PEREIRA, J.D.B.; VILANOVA, M.S.; GIACOMET, C.D.B. et al. Comportamento ingestivo de potros da raça Crioula com 5 meses de idade na fase de cria. Rev. Acad. Ciênc. Anim., v.15, p.195-196, 2017.

RANGEL, A.H.N.; GALVÃO JUNIOR, J.G.B.; SIMPLICIO, A.A. et al. Aspectos composicionais e nutricionais do leite de jumenta: uma revisao. Rev. Inst. Latic. Cândido Tostes, v.70, p.160-171, 2015.

SCHRYVER, H.; OFTEDAL, O.T.; WILLIAMS, J. et al. Lactation in the horse: the mineral composition of mare milk. J. Nutr., v.116, p.2142-2147, 1986.

SISSON, S. Tegumento comum. In: GETTY, R.; SISSON, S.; GROSSMAN, J.D. Sisson \& Grossman anatomia dos animais domésticos. Rio de Janeiro: Guanabara Koogan, 1986. p681-688.

SMART, M.; CYMBALUK, N. Role of nutritional supplements in bovine lameness: review of nutritional toxicities. 3.ed. Weaver: WB Saunders, 1997.

SOUZA, J.R.M.D.; PIMENTEL, A.M.H.; FOLLE, V.A. et al. Morphometric changes in the hoof capsule of Criollo foals from birth to weaning. Cienc. Rural, v.47, n.7, 5p. 2017.

TOMLINSON, D.; MÜLLING, C.; FAKLER, T. Invited review: formation of keratins in the bovine claw: roles of hormones, minerals, and vitamins in functional claw integrity. J. Dairy Sci., v.87, p.797-809, 2004.

VAN RIET, M.M.; MILLET, S.; ALUWÉ, M. et al. Impact of nutrition on lameness and claw health in sows. Livest. Sci., v.156, p.24-35, 2013.

WINKLER, B.; MARGERISON, J. Mechanical properties of the bovine claw horn during lactation. J. Dairy Sci., v.95, p.1714-1728, 2012. 